\title{
Early recurrence of hepatocellular carcinoma in patients with HCV infection followed by transient elastography for two years after successful treatment with daclatasvir plus asunaprevir
}

\author{
Noboru Hirashima $^{* 1}$, Hiroaki Iwase ${ }^{1}$, Masaaki Shimada ${ }^{1}$, Nobumitsu Ryuge ${ }^{1}$, Noboru Urata ${ }^{1}$, Etsuko Iio ${ }^{2}$ and Yasuhito Tanaka ${ }^{2}$ \\ ${ }^{1}$ Department of Gastroenterology, National Hospital Organization Nagoya Medical Center, Nagoya, Japan \\ ${ }^{2}$ Department of Virology and Liver Unit, Nagoya City University Graduate School of Medical Sciences, Nagoya, Japan
}

\begin{abstract}
Aim and background: Recent advances have been achieved in HCV treatments because direct-acting antivirals (DAA) result in a sustained viral response (SVR) in more than $90 \%$ of HCV-infected patients, even those with severe fibrosis. However, an unexpected high rate of HCC recurrence following DAA has been reported. The aim of this study was to prospectively evaluate the relationship between the occurrence or recurrence of HCC and regression of fibrosis followed by transient elastography for two years after successful treatment with daclatasvir plus asunaprevir (DCV plus ASV) in patients with HCV infection.

Method: Forty-four patients who were treated with DCV plus ASV for 24 weeks and achieved SVR were followed-up for two years and analyzed. Eight patients had a history of being treated for HCC by radiofrequency ablation (RFA) or resection. Transient elastography (Fibroscan $\left.{ }^{\circledR}\right)$ with liver stiffness measurements (LSM) was performed at the initiation of DCV plus ASV, at the end of the treatment (EOT), and 24 and 72 weeks after the treatment.

Results: The occurrence of HCC was not detected during the follow-up. Three out of eight patients with a history of HCC treatment subsequently developed radiological HCC recurrence a few months after the treatment with DCV plus ASV. LSM values measured by Fibroscan at the initiation of DCV plus ASV increased to $19.1,13.1$, and $26.0 \mathrm{kPa}$ in Cases 1, 2, and 3, respectively, while those at EOT were 12.8, 12.0, and 26.6 kPa, respectively. The five other patients with LSM values less than $12 \mathrm{kPa}$ at the last Fibroscan have shown no recurrence.

Conclusion: Chronic hepatitis $\mathrm{C}$ patients previously treated for HCC with high LSM values before and after DAA may be at a high risk of HCC recurrence, suggesting that strict HCC surveillance is required even after the achievement of SVR by DAA.
\end{abstract}

\section{Introduction}

Since 2013, IFN-free, direct-acting antiviral agents (DAA) represent an important opportunity for improving the treatment of $\mathrm{HCV}$ in patients with hepatitis $\mathrm{C}$, and have shown superior efficacy and the amelioration of adverse events [1-6]. In Japan, daclatasvir (DCV) plus asunaprevir (ASV) was the first-generation treatment option approved for chronic HCV genotype 1b patients in September 2014 [5]. Without a previous history of simeprevir therapy and pre-existing NS5A Y93H, DCV plus ASV was reported to be approximately $90 \%$ effective for patients with HCV genotype 1b [7]. DAA were recently shown to achieve sustained virological responses (SVR) in more than $90 \%$ of HCV-infected patients, even those with severe fibrosis. However, an unexpected high rate of HCC recurrence following DAA has been reported [8]. In previous studies on interferon (IFN)-based antiviral treatments for chronic hepatitis C, SVR decreased the longterm risk of HCC in patients with advanced fibrosis [9]. On the other hand, SVR patients following interferon-based treatments showed the significant regression of liver stiffness measurements (LSM) [10]. In the present study, among eight patients infected with HCV genotype $1 \mathrm{~b}$ who achieved SVR by DCV plus ASV for 24 weeks after the treatment of HCC by radiofrequency ablation (RFA) or resection, three with high LSM values subsequently developed radiological HCC recurrence a few months after the achievement of SVR.

\section{Patients and methods}

This study included 44 patients infected with HCV genotype $1 \mathrm{~b}$ who were treated with DCV plus ASV for 24 weeks, achieved SVR, and was followed-up for two years. The baseline characteristics of the patients included in this study are shown in Table 1 . There were 28 IFN-ineligible patients: 5 with diabetes mellitus, 6 with depression, 4 with idiopathic thrombocytopenia, 1 with paroxysmal nocturnal hemoglobinuria, 2 with myocardial infarction, 1 with non-tuberculosis mycobacteria 1,4 with collagen disease, and 5 older than 75 years of age. There were 3 IFN-intolerant patients: 2 with retinal hemorrhage and 1 with vertebritis. Eight patients achieved complete responses after the previous treatment of HCC by RFA or resection before the initiation of

Correspondence to: Dr. Noboru Hirashima, Department of Gastroenterology, National Hospital Organization Nagoya Medical Center. 4-1-1 Sannomaru, Naka-Ku, Nagoya 460-0001, Japan; Tel: +81-52-951-1111; Fax: +81-52-9510664; E-mail: hirasima@nnh.hosp.go.jp

Key words: hepatitis $C$ virus genotype $1 b$, daclatasvir, asunaprevir, hepatocellular carcinoma, recurrence, liver stiffness measurement

Received: January 28, 2017; Accepted: February 18, 2017; Published: February 21,2017 
Hirashima N (2017) Early recurrence of hepatocellular carcinoma in patients with HCV infection followed by transient elastography for two years after successful treatment with daclatasvir plus asunaprevir

DCV plus ASV. The median LSM value was $11.1(3.8-28.8) \mathrm{kPa}$, with the number of patients with $\mathrm{LSM}<12.0$ and $\geq 12.0 \mathrm{kPa}$ being 26 and 18, respectively. There were 36 patients with a Child Pugh score of 5 and 8 with a score of 6 ; none of the patients exhibited decompensated cirrhosis. Table 2 showed the previous history of HCC treatment before DCV plus ASV. Only one HCC nodule was present in each patient. Previous studies reported that the existence of pre-treatment variants in the NS3A and NS5A regions affected the outcomes of DCV plus ASV combination therapy $[5,11,12]$. Therefore, variants associated with L31 and Y93 in the NS5A region of the HCV genome in pretreatment patient serum were tested using a direct sequencing method $[12,13]$ because the variants associated with Y93 and L31 in the NS5A region are known to be the most strongly associated with treatment outcomes $[5,11,12]$. NS5A variants were confirmed to be absent in all patients before the initiation of DCV plus ASV. All patients were administered $60 \mathrm{mg}$ DCV (Daklinza ${ }^{\circledR}$; Bristol-Myers KK, Tokyo, Japan) once daily and $100 \mathrm{mg}$ ASV (Sunvepra ${ }^{\circledR}$; Bristol-Myers KK, Tokyo, Japan) twice daily for 24 weeks between December 2014 and August 2015. Blood chemistry examinations and patient interviews were conducted every two weeks after the initiation of the treatment in order to detect adverse events. Virological responses were assessed 24 weeks after the completion of the treatment. SVR24 was defined as undetectable serum HCV RNA 24 weeks after the completion of the treatment. All patients were confirmed to have no HCC recurrence using abdominal computed tomography (CT) or magnetic resonance (MR) and ultrasound (US) before the initiation of DCV plus ASV.

\section{Follow-up of patients}

HCC was diagnosed based on the pattern of nodules on contrastenhanced $\mathrm{CT}$ and gadolinium ethoxybenzyl diethylenetriamine pentaacetic acid (Gd-EOB-DTPA)-enhanced MR. CT or MR was performed every 6 months during the follow-up. Transient elastography (Fibroscan ${ }^{\circledR}$ ) with LSM was prospectively performed at the initiation of DCV plus ASV, at the end of the treatment (EOT), and 24 and 72 weeks after the treatment. Statistical analysis

Quantitative variables were shown as medians (minimummaximum). LSM values were compared using the $t$-test (parametric data). $\mathrm{P}<0.05$ was defined as significant.

\section{Results}

\section{Development of HCC (Table 2)}

The occurrence of HCC was not detected during the follow-up. Three out of eight patients developed radiological HCC recurrence a few months after the treatment with DCV plus ASV. Case 1 is a 56-year-old male. Six months before DCV plus ASV, a 13-mm HCC nodule at segment 8 was detected on $\mathrm{CT}$ and he was treated with RFA. Three months after the HCV treatment, recurrence of the 13mm HCC nodule at segment 7 was detected on CT and he was treated with Proton therapy. LSM values at SVR24 and 72 were 11.8 and 14.4 $\mathrm{kPa}$, respectively, which were still high. Case 2 is a 68 -year-old female. Fourteen months before DCV plus ASV, a $15-\mathrm{mm}$ HCC nodule at segment 8 was detected on $\mathrm{CT}$ and she underwent liver resection. Her LSM value at EOT was $12.0 \mathrm{kPa}$, which was high. Three months after the HCV treatment, recurrence of the 15-mm HCC nodule at segment 6 was detected on MR and she was treated with RFA. LSM values at SVR2 4 and 72 were 10.1 and $6.8 \mathrm{kPa}$, respectively. Case 3 is a 65 -yearold male. Four months before DCV plus ASV, a 20-mm HCC nodule at segment 6 was detected on MR and he was treated with RFA. His LSM value at EOT was $20.4 \mathrm{kPa}$, which was high. Five months after the HCV treatment, recurrence of the $15-\mathrm{mm}$ HCC nodule at segment 3 was detected on MR and he was treated with RFA. His LSM value at SVR24 was $26.0 \mathrm{kPa}$, which was still high. LSM values measured by Fibroscan at the initiation of DCV plus ASV increased to 19.1, 13.1, and $26.0 \mathrm{kPa}$ in Cases 1, 2, and 3, respectively, showing the development of liver cirrhosis [14]. LSM values at EOT were $12.8,12.0$, and $26.6 \mathrm{kPa}$, respectively, while the five other patients with LSM values less than 12 $\mathrm{kPa}$ at the last Fibroscan have shown no recurrence.

\section{Variations in LSM during the 2-year follow-up}

Twenty-four patients underwent LSM at the time of starting DCV plus ASV $<12.0 \mathrm{kPa}$ without HCC (Figure a). Their LSM values at the initiation of DCV plus ASV, at EOT, and 24 and 72 weeks after the treatment were 7.2 (3.8-11.8), 6.1 (2.6-14.0), 5.4 (3.2-7.8), and 4.7 (3.38.1) $\mathrm{kPa}$, respectively, showing significant improvements (Figure a). Twelve patients underwent LSM at the time of starting DCV plus ASV

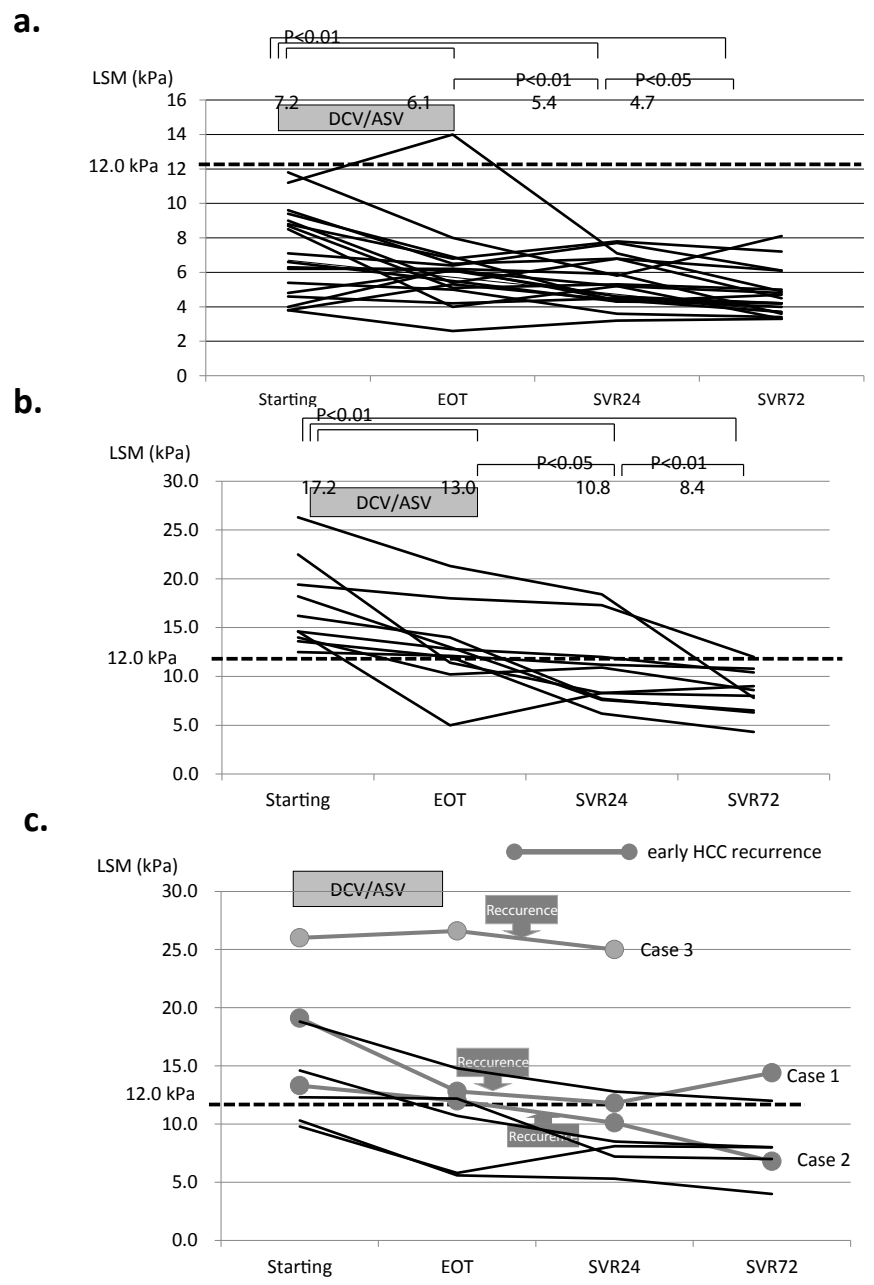

Figure 1. a. Twenty-four patients underwent LSM at the time of starting DCV/ASV $<12.0$ $\mathrm{kPa}$ without HCC. Their LSM values at the initiation of DCV plus ASV, at the end of the treatment (EOT), and 24 and 72 weeks after the treatment significantly improved: 7.2 (3.811.8), 6.1 (2.6-14.0), 5.4 (3.2-7.8), and $4.7(3.3-8.1) \mathrm{kPa}$, respectively. DCV: daclatasvir, ASV: asunaprevir. b. Twelve patients underwent LSM at the time of starting DCV plus ASV $\geq 12.0 \mathrm{kPa}$ without HCC. Their LSM values also significantly improved: $17.2(12.5-28.8)$ $13.0(5.0-21.3), 10.8(6.2-18.4)$ and $8.4(4.3-12.0) \mathrm{kPa}$, respectively, ultimately reaching less than $12 \mathrm{kPa}$. DCV: daclatasvir, ASV: asunaprevir. c. LSM values of three recurrent HCC patientsat the initiation of DCV plus ASV increased to $19.1,13.1$, and $26.0 \mathrm{kPa}$ respectively, and LSM values at EOTwere $12.8,12.0$, and $26.6 \mathrm{kPa}$, respectively, while five other patients with LSM values less than $12 \mathrm{kPa}$ at the last Fibroscan have shown no recurrence. DCV: daclatasvir, ASV: asunaprevir. 
Hirashima N (2017) Early recurrence of hepatocellular carcinoma in patients with HCV infection followed by transient elastography for two years after successful treatment with daclatasvir plus asunaprevir

$\geq 12.0 \mathrm{kPa}$ without HCC (Figure b). Their LSM values also significantly improved: 17.2 (12.5-28.8), 13.0 (5.0-21.3), 10.8 (6.2-18.4) and $8.4(4.3-$ 12.0) $\mathrm{kPa}$ at the initiation of DCV plus ASV, at EOT, and 24 and 72 weeks after the treatment, respectively, ultimately reaching less than $12 \mathrm{kPa}$ (Figure b). LSM values in the 3 patients with recurrent HCC at the initiation of DCV plus ASV increased to $19.1,13.1$, and $26.0 \mathrm{kPa}$, respectively, while LSM values at EOT were $12.8,12.0$, and $26.6 \mathrm{kPa}$, respectively. The five other patients with LSM values less than $12 \mathrm{kPa}$ at the last Fibroscan have shown no recurrence (Figure c).

\section{Discussion}

In the present study, among eight patients infected with HCV genotype $1 \mathrm{~b}$ who achieved SVR by DCV plus ASV for 24 weeks after complete responses to the treatment of HCC by ablation or resection (only one HCC nodule was present in each patient), three subsequently developed radiological HCC recurrence after a few months. In the study by Reig M [8], some patients were treated with TACE, which is potentially non-curative because of its characteristic of a high early recurrence rate. Although all our patients were treated with potentially curative treatments, resection and RFA, HCC recurrence occurred a few months after DCV plus ASV.

Fibroscan with LSM was prospectively performed at the initiation of DCV plus ASV, at EOT, and 24 and 72 weeks after the treatment. LSM values measured by Fibroscan increased to 19.1, 13.1, and 26.0 $\mathrm{kPa}$ in Cases 1, 2, and 3, respectively, showing the development of liver cirrhosis. Since an LSM value of more than $12.0 \mathrm{kPa}$ was previously reported to indicate severe fibrosis [14], we considered it important to start the treatment of HCV as soon as possible. Conti F, et al. showed that, in an analysis of 59 patients with a previous history of HCC, patients with LSM $>21.5 \mathrm{kPa}$ before DAA were significantly more likely to show HCC recurrence [15]. LSM $>21.5 \mathrm{kPa}$ is assumed to be liver cirrhosis, and that of Case 3 only was $>21.5 \mathrm{kPa}$. Cheung M C M, et al. found that DAA therapy in patients with decompensated cirrhosis did not decrease the occurrence of HCC [16]. However, Conti F, et al. did not examine changes in LSM during the prospective followup. Therefore, we analyzed changes in LSM in eight patients with a previous history of HCC during a follow-up of two years. LSM values at the initiation of DCV plus ASV increased to $19.1,13.1$, and $26.0 \mathrm{kPa}$ in Cases 1, 2, and 3, respectively, showing the development of liver cirrhosis. Moreover, LSM values at EOT were 12.8, 12.0, and $26.6 \mathrm{kPa}$, respectively, which were high before the recurrence of HCC. On the other hand, the LSM values of the other 5 cases without recurrence gradually decreased to less than $12.0 \mathrm{kPa}$ between EOT and 72 weeks after DCV plus ASV. In HCV patients previously treated for HCC with high LSM values not only before, but also after DAA, the risk of HCC recurrence may still be high.

SVR patients following interferon-based treatments showed the significant regression of LSM [10]. Furthermore, in SVR patients treated with DAA, LSM values were significantly reduced during follow-ups $[17,18]$; this early improvement was attributed to a decrease in inflammation. LSM values showed further significant decreases during the subsequent follow-up, even in the other 5 cases without recurrence (Table 1). Since artifacts due to liver inflammation were no longer implicated, decreases in LSM values at EOT and SVR24 and 72 may reflect a genuine and progressive reduction in fibrosis (Figure a, b). However, LSM values at EOT were 12.8, 12.0, and $26.6 \mathrm{kPa}$ in Cases 1,2 , and 3, respectively, which were high without the regression of fibrosis before HCC recurrence. In patients previously treated for HCC with high LSM values before and after DAA, the risk of HCC recurrence may be high. The effects of DAA on the occurrence and recurrence of HCC currently remain unknown because of a lack of evidence [19]. A large prospective study with properly selected populations and a long-term follow-up needs to be conducted. Furthermore, the extent to which the regression of LSM decreases the risk of HCC recurrence after DAA achieving SVR needs to be estimated in a large number of cases.

Table 1. Baseline characteristics of patients included in this study $(\mathrm{n}=44)$.

\begin{tabular}{|c|c|}
\hline Age (year) & $70(39-84)$ \\
\hline Male : Female & $15: 29$ \\
\hline Duration of the follow-up (months) & $22(17-28)$ \\
\hline IFN ineligible : intolerant & $28^{*}: 3^{* *}$ \\
\hline Non-responder : Relapse & $11: 3$ \\
\hline \multicolumn{2}{|l|}{ History of HCC treatment with a complete response 8} \\
\hline Resection : Ablation & $2: 6$ \\
\hline HCV RNA (Log IU/ml) & $6.2(4.0-7.4)$ \\
\hline White cell count $(/ \mu \mathrm{l})$ & $4800(1500-10600)$ \\
\hline Hemoglobin (g/dl) & $13.6(7.3-17.2)$ \\
\hline Platelets $\left(10^{4} / \mu \mathrm{I}\right)$ & $15.5(6.9-28.4)$ \\
\hline Aspartate aminotransferase (IU/L) & $42(20-234)$ \\
\hline Alanine aminotransferase (IU/L) & $44(18-389)$ \\
\hline$\gamma$-Glutamyltransferase (IU/L) & $36(15-55)$ \\
\hline Total Bilirubin (mg/dl) & $0.70(0.34-1.94)$ \\
\hline Albumin (g/dl) & $4.1(2.8-5.2)$ \\
\hline Creatinine (mg/dl) & $0.73(0.46-1.63)$ \\
\hline Alpha-fetoprotein (ng/ml) & $5(1-450)$ \\
\hline Fib-4 & $3.21(0.87-9.66)$ \\
\hline$<3.25: \geq 3.25$ & $23: 21$ \\
\hline Liver stiffness (kPa) & $11.1(3.8-28.8)$ \\
\hline$<12.0: \geq 12.0$ & $26: 18$ \\
\hline Child Pugh score & $36: 8$ \\
\hline
\end{tabular}

*Diabetes mellitus 5, Depression 6, Idiopathic thrombocytopenia 4, Paroxysmal nocturnal hemoglobinuria 1, Myocardial infarction 2, Non-tuberculosis mycobacteria 1, Collagen disease 4 , older than 75 years 5. **Retinal hemorrhage 2, Vertebritis 1 
Hirashima N (2017) Early recurrence of hepatocellular carcinoma in patients with HCV infection followed by transient elastography for two years after successful treatment with daclatasvir plus asunaprevir

Table 2. Courses of HCCbefore and LSM after the treatment with DCV/ASV in 8 cases.

\begin{tabular}{|c|c|c|c|c|c|c|c|c|c|}
\hline \begin{tabular}{|l|}
3 Cases \\
with \\
recurrence
\end{tabular} & Age & Gender & & $\begin{array}{l}\text { Before or } \\
\text { after DCV/ } \\
\text { ASV } \\
\text { (months) }\end{array}$ & $\begin{array}{l}\text { Pattern of } \mathrm{HCC} * \\
\text { (Imaging technique/Location/Size/ } \\
\text { Treatment) }\end{array}$ & & LSM (kPa) & & \\
\hline & & & & & & $\begin{array}{l}\text { At the initiation of } \\
\text { DCV/ASV }\end{array}$ & EOT & SVR24 & SVR72 \\
\hline \multirow[t]{2}{*}{1} & 56 & M & At the occurrence of HCC & -6 & $\mathrm{CT} / \mathrm{S} 8 / 13 \mathrm{~mm} / \mathrm{RFA}$ & 19.1 & 12.8 & 11.8 & 14.4 \\
\hline & & & At the recurrence of $\mathrm{HCC}$ & +3 & $\mathrm{CT} / \mathrm{S} 7 / 13 \mathrm{~mm} /$ Proton therapy & & & & \\
\hline \multirow[t]{2}{*}{2} & 65 & F & At the occurrence of HCC & -14 & $\mathrm{CT} / \mathrm{S} 8 / 15 \mathrm{~mm} /$ Resection & 13.3 & 12.0 & 10.1 & 6.8 \\
\hline & & & At the recurrence of $\mathrm{HCC}$ & +3 & $\mathrm{MR} / \mathrm{S} 6 / 15 \mathrm{~mm} / \mathrm{RFA}$ & & & & \\
\hline \multirow[t]{2}{*}{3} & 65 & M & At the occurrence of $\mathrm{HCC}$ & -4 & $\mathrm{MR} / \mathrm{S} 6 / 20 \mathrm{~mm} / \mathrm{RFA}$ & 26.0 & 26.6 & 26.0 & \\
\hline & & & At the recurrence of $\mathrm{HCC}$ & +5 & $\mathrm{MR} / \mathrm{S} 3 / 15 \mathrm{~mm} / \mathrm{RFA}$ & & & & \\
\hline \multirow[t]{2}{*}{$\begin{array}{l}5 \text { other } \\
\text { caseswithout } \\
\text { recurrence }\end{array}$} & Age & Gender & & $\begin{array}{l}\text { Before DCV/ } \\
\text { ASV } \\
\text { (months) }\end{array}$ & $\begin{array}{l}\text { Pattern of } \mathrm{HCC}^{*} \\
\text { (Imaging technique/Location/Size/ } \\
\text { Treatment) }\end{array}$ & & LSM (kPa) & & \\
\hline & & & & & & $\begin{array}{l}\text { At the initiation of } \\
\text { DCV/ASV }\end{array}$ & EOT & SVR24 & SVR72 \\
\hline 4 & 80 & M & At the occurrence of $\mathrm{HCC}$ & -19 & $\mathrm{CT} / \mathrm{S} 4 / 18 \mathrm{~mm} / \mathrm{RFA}$ & 18.8 & 14.8 & 12.8 & 12.0 \\
\hline 5 & 74 & M & At the occurrence of $\mathrm{HCC}$ & -3 & $\mathrm{MR} / \mathrm{S} 4 / 10 \mathrm{~mm} / \mathrm{RFA}$ & 14.6 & 10.7 & 8.5 & 8.0 \\
\hline 6 & 84 & M & At the occurrence of $\mathrm{HCC}$ & -8 & $\mathrm{MR} / \mathrm{S} 4 / 10 \mathrm{~mm} / \mathrm{RFA}$ & 12.3 & 12.2 & 7.2 & 7.0 \\
\hline 7 & 78 & M & At the occurrence of HCC & -12 & $\mathrm{CT} / \mathrm{S} 8 / 30 \mathrm{~mm} /$ Resection & 10.3 & 5.6 & 5.3 & 4.0 \\
\hline 8 & 71 & M & At the occurrence of HCC & -6 & $\mathrm{CT} / \mathrm{S} 3 / 12 \mathrm{~mm} / \mathrm{RFA}$ & 9.8 & 8.8 & 8.1 & 8.0 \\
\hline
\end{tabular}

*one nodule in each patient

DCV/ASV: daclatasvir plus asunaprevir, LSM: liver stiffness measurement ( $\geq 12.5 \mathrm{kPa}$ indicates liver cirrhosis), ETO: end of the treatment, SVR: sustained viral response, RFA: radiofrequency ablation.

\section{Conclusion}

In conclusion, $\mathrm{HCV}$ patients previously treated for HCC with high LSM values before and after DAA are still at a high risk of HCC recurrence, and need to be closely monitored while LSM values are high, even after the achievement of SVR.

\section{Conflict of interest}

Noboru Hirashima, Hiroaki Iwase, Masaaki Shimada, Nobumitsu Ryuge, Noboru Urata, and Etsuko Iio have no conflict of interest. Yasuhito Tanaka received lecture fees from Bristol-Myers Squibb Company, MSD K.K., Chugai Pharmaceutical Co., Ltd., Janssen Pharmaceutical K.K., and Gilead Sciences. Yasuhito Tanaka received Commercial research funding from Bristol-Myers Squibb Company, Chugai Pharmaceutical Co., Ltd., and AbbVie Inc.

\section{Human rights}

All procedures followed have been performed in accordance with the ethical standards laid down in the 1964 Declaration of Helsinki and its later amendments.

\section{Informed consent}

Informed consent was obtained from all patients before their inclusion in this study.

\section{References}

1. Lawitz E, Sulkowski MS, Ghalib R, Rodriguez-Torres M, Younossi ZM, et al. (2014) Simeprevir plus sofosbuvir, with or without ribavirin, to treat chronic infection with hepatitis $\mathrm{C}$ virus genotype 1 in non-responders to pegylated interferon and ribavirin and treatment-naive patients: the COSMOS randomised study. Lancet 384: 1756-1765. [Crossref]

2. Poordad F, Hezode C, Trinh R, Kowdley KV, Zeuzem S, et al. (2014) ABT-450/rombitasvir and dasabuvir with ribavirin for hepatitis $\mathrm{C}$ with cirrhosis. $N$ Engl $\mathrm{J} \mathrm{Med}$ 370: 1973-1982.[Crossref]
3. Lawitz E, Gane E, Pearlman B, Tam E, Ghesquiere W, et al. (2015)Efficacy and safety of 12 weeks versus 18 weeks of treatment with grazoprevir (MK-5172) and elbasvir (MK-8742) with or without ribavirin for hepatitis C virus genotype 1 infection in previously untreated patients with cirrhosis and patients with previous null response with or without cirrhosis (C-WORTHY): a randomised, open-label phase 2 trial. Lancet 385: 1075-1086. [Crossref]

4. Afdhal N, Reddy KR, Nelson DR, Lawitz E, Gordon SC, et al. (2014) Ledipasvir and sofosbuvir for previously treated HCV genotype 1 infection. N Engl J Med 370: 14831493.[Crossref]

5. Kumada H, Suzuki Y, Ikeda K, Toyota J, Karino Y, et al. (2014) Daclatasvir plus asunaprevir for chronic HCV genotype 1b infection. Hepatology 59: 2083-2091. [Crossref]

6. Manns M, Pol S, Jacobson IM, Marcellin P, Gordon SC, et al. (2014) All-oral daclatasvir plus asunaprevir for hepatitis $\mathrm{C}$ virus genotype $1 \mathrm{~b}$ : a multinational, phase 3 , multicohort study. Lancet 384: 1597-1605. [Crossref]

7. Iio E, Shimada N, Abe H, Atsukawa M, Yoshizawa K, et al. (2016) Efficacy of daclatasvir/asunaprevir according to resistance-associated variants in chronic hepatitis c with genotype1. J Gastoenterol 52: 94-103. [Crossref]

8. Reig M, Mariño Z, Perelló C, Iñarrairaegui M, Ribeiro A, et al. (2016) Unexpected high rate of early tumor recurrence in patients with HCV-related HCC undergoing interferon-free therapy. J Hepatol 65: 719-726.[Crossref]

9. Morgan, RL, Baack B, Smith BD, Yartel A, Pitasi M, et al. (2013) Eradication of hepatitis $\mathrm{C}$ virus infection and the development of hepatocellular carcinoma: a metaanalysis of observational studies. Ann. Inten. Med 158: 329-337. [Crossref]

10. Masias J, Rivero A, Cifucentes C, Camacho A, Neukam K, et al. (2013) Sustained viral response to pegylated interferon plus ribavirin leads to normalization of liver stiffness in hepatitis C virus-infected patients. Enferm Infec Microbil Clin 31: 424-429. [Crossref]

11. Karino Y, Toyota J, Ikeda K, Suzuki F, Chayama K, et al. (2013) Characterization of virologic escape in hepatitis $\mathrm{C}$ virus genotype $1 \mathrm{~b}$ patients treated with the direct-acting antivirals daclatasvir and asunaprevir. J Hepatol 58: 646-654. [Crossref]

12. McPhee F, Suzuki Y, Toyota J, Karino Y, Chayama K, et al. (2015) High Sustained Virologic Response to Daclatasvir Plus Asunaprevir in Elderly and Cirrhotic Patients with Hepatitis C Virus Genotype 1b Without Baseline NS5A Polymorphisms. Adv Ther 32: 637-649. [Crossref]

13. McPhee F, Hernandez D, Yu F, Ueland J, Monikowski A, et al. (2013) Resistance analysis of hepatitis $\mathrm{C}$ virus genotype 1 prior treatment null responders receiving 
Hirashima N (2017) Early recurrence of hepatocellular carcinoma in patients with HCV infection followed by transient elastography for two years after successful treatment with daclatasvir plus asunaprevir

daclatasvir and asunaprevir. Hepatology 58: 902-911. [Crossref]

14. Castera L, Forns X, Alberti A (2008) Non-invasive evaluation of liver fibrosis using transient elastography. J Hepatol 48: 835-847.[Crossref]

15. Conti F, Buonfiglioli f, Scuteri A, Crespi C, Bolondi L,et al. (2016) Early occurrence and recurrence of hepatocellular carcinoma in HCV-related cirrhosis treated with direct-acting antivirals. J Hepatol 65: 727-733. [Crossref]

16. Cheung MCM, Walker AJ, Hudson BE, Verma S, McLauchlan J, et al. (2016) Outcome after successful direct-acting antiviral therapy for patients with chronic hepatitis $\mathrm{C}$ and decompensated cirrhosis. J Hepatol 65: 741-747. [Crossref]
17. Bachofner JA, Valli PV, Kroger A, Bergamin I, Künzler P, et al. (2016) Direct antiviral agent treatment of chronic hepatitis $\mathrm{C}$ results in rapid regression of transient elastography and fibrosis markers fibrosis- 4 score and aspartate aminotransferaseplatelet ratio index. Liver Int 10.1111/liv.13256. [Crossref]

18. Martini S, Sacco M, Strona S, Arese D, Tandoi F,et al. (2016) Impact of viral eradication with sofosbuvir-based therapy on the outcome of post-transplant hepatitis $\mathrm{C}$ with sever fibrosis. Liver Int 37: 62-70. [Crossref]

19. The ANRS collaborative study group on hepatocellular carcinoma (2016) Lack of evidence of an effect of direct-acting antivirals on the recurrence of hepatocellular carcinoma: Data from three ANRS cohorts. J Hepatol 65: 734-740. [Crossref]

Copyright: @2017 Hirashima N. This is an open-access article distributed under the terms of the Creative Commons Attribution License, which permits unrestricted use, distribution, and reproduction in any medium, provided the original author and source are credited. 